\title{
OS ECOS DAS IRMANDADES DA FALA EN CUBA (1900-1925)
}

\author{
Alfonso Iglesias Amorín \\ Universidade de Santiago de Compostela
}

DOI: 10.17075/iftpc.2021.012 



\section{INTRODUCIÓN}

As Irmandades da Fala, eixe central deste volume, supuxeron unha experiencia senlleira dentro do galeguismo, ata o punto de que en boa medida marcaron o paso do rexionalismo ao nacionalismo na súa definición ideolóxica. En Galicia foron moitas as agrupacións desta índole que se crearon a partir de 1916, comezando pola da Coruña, a primeira e máis importante, e seguindo coas de Santiago, Monforte, Pontevedra, Ourense, Vilalba, Ferrol, Betanzos e unha longa nómina. Mais o territorio galego non foi unha fronteira para a extensión destas agrupacións, e a diáspora galega non perdeu a oportunidade de reproducilas fóra do país, na Habana e Bos Aires, o que tamén achegaba unha boa mostra das cidades onde a comunidade galega externa a Galicia tiña unha maior relevancia.

No caso da Habana, que case en exclusiva capitalizou as actividades galeguistas na illa de Cuba, non só foi unha cidade que tería a súa propia Irmandade coa creación en 1920 da Xuntanza Nazonalista Galega (XNG), senón que ademais constituiría un foco irradiador de iniciativas que permitiron avanzar nese xurdimento dunha conciencia nacional galega. O seu papel decisivo na creación da Academia Galega, que foi concibida e financiada nos seus primeiros tempos dende Cuba, é un dos mellores exemplos diso. Entre finais do século XIX e os primeiros anos do XX a illa caribeña, e nomeadamente A Habana, pode ser considerada como a capital do galeguismo, de maneira que resulta imposible entender o seu desenvolvemento político-ideolóxico neses anos sen ter en conta o seu impacto.

A importancia da emigración americana na evolución dos nacionalismos subestatais europeos non é en absoluto exclusiva do nacionalismo galego. Tamén 
se dá noutros casos europeos, como o irlandés ${ }^{1}$. A asunción de postulados nacionalistas nestas comunidades emigrantes que estaban lonxe da súa patria, e que a miúdo eran prósperas economicamente, favoreceu que en moitos casos se convertesen en financiadoras e alentadoras dos movementos nacionalistas que se desenvolvían no propio país de orixe.

\section{CUBA, GRAN CENTRO CULTURAL GALEGO A COMEZOS DO SÉCULO XX}

Na segunda metade do século XIX a emigración dos galegos cara ao continente americano, ata entón pouco numerosa, acadou uns ritmos verdadeiramente elevados. Dentro dos destinos, a estrela foi con diferenza a illa de Cuba, que aínda era territorio colonial español. O incremento das tensións independentistas xeradas polo nacionalismo cubano e a súa crecente forza levaron ás autoridades españolas a fomentar con especial interese esa emigración, que non só servía para fornecer de man de obra a illa, senón tamén para «españolizala», nun intento de reducir o peso proporcional dos independentistas cubanos na poboación.

$\mathrm{O}$ aumento do continxente inmigrante galego en Cuba, concentrado maiormente na Habana, propiciou a creación de diferentes asociacións para defender os intereses comúns dos emigrantes ${ }^{2}$. Estes centros galegos comezaron a funcionar como catalizadores dun proceso de asociacionismo étnico, e tamén axudaron a artellar unha colectividade que non paraba de recibir novos individuos ${ }^{3}$.

\footnotetext{
1 Xosé M. Núñez Seixas (1992): O galeguismo en América, 1879-1936, Sada, Ediciós do Castro.

2 Para termos unha idea do peso da colectividade galega, calcúlase que entre 1899 e 1933 ata 361232 galegos emigraron á illa, o que supón unha cifra impresionante tendo en conta que Galicia roldaba os dous millóns de habitantes á altura de 1900; José Antonio Vidal Rodríguez (2008): A Galicia antillana: formación e destrución da identidade galega en Cuba, 1899-1968, Santiago de Compostela, Fundación Pedro Barrié de la Maza, 25.

3 Xosé M. Núnez Seixas (1998): Emigrantes, caciques e indianos: o influxo sociopolitico da emigración transoceánica en Galicia (1900-1930), Vigo, Xerais, 74.
} 
O Centro Galego da Habana converteuse no eixe central deste proceso e acadou unha enorme influencia sobre a comunidade galega na illa. A súa fundación tivo lugar en 1879 e destaca entre os seus impulsores o avogado e xornalista Waldo Álvarez Ínsua. Dende a súa concepción, os seus obxectivos fundamentais foron dar formación aos inmigrantes para combater o elevado analfabetismo co que viñan de Galicia, defender os dereitos dos traballadores galegos para evitar condicións laborais abusivas e fomentar a cultura galega. Con este último obxectivo organizáronse ensinanzas diversas, creouse unha biblioteca, fixéronse seccións de Filharmonía e Declamación, colaborouse con grupos artísticos como o Cuerpo de Baile Gallego e a coral Aires da Miña Terra e financiouse a publicación dos primeiros volumes da monumental Historia de Galicia de Murguía. Moitos labores en moi diversos eidos que converteron o Centro Galego nun referente para a cultura galega, xa non só en Cuba, senón globalmente. Orientado na liña do rexionalismo, publicou obras e promoveu diversas iniciativas galeguistas. Ademais, o Centro Galego non traballou só polos galegos de Cuba, senón polos galegos en xeral, e por iso a miúdo tentou influír nos Gobernos españois para defender intereses de Galicia e enviou achegas económicas coincidindo con catástrofes naturais. Tamén foron frecuentes as campañas a prol da boa imaxe de Galicia e dos inmigrantes galegos no seu conxunto, co fin de combater o estereotipo étnico negativo que imperaba entre boa parte da opinión pública cubana e entre a latinoamericana en xeral.

Á marxe do Centro Galego, houbo moitas outras asociacións galegas -superaban as cen a comezos do XX-, case todas na Habana e con moi diversos fins; sobrancearon entre elas as asociacións microterritoriais ou de instrución a partir de $1904^{4}$. Tamén cómpre destacar a importancia da prensa galega na illa, con cabeceiras que alcanzaron certa notoriedade, como El Eco de Galicia ou La Tierra

4 Cf. Xosé M. Núñez Seixas (2019): «Galician Immigrant Societies in Cuba: Local Identity, Diaspora Politics and Atlantic Mobilization (1870-1940)», Journal of Social History, 52:3, 705-730. 
Gallega, e que serviron de voceiros para os intereses prácticos da comunidade galega, pero tamén para a difusión cultural. O semanario El Eco de Galicia foi fundado en 1879 polo propio Waldo Álvarez Ínsua e dende o primeiro momento apareceu como un claro defensor da causa rexionalista. Durou ata 1902, cando a súa liña foi continuada por Galicia, que pola súa vez se publicou ata 1930. Estes dous xornais constituíron os voceiros máis estables do galeguismo na illa nunha época na que a maioría das cabeceiras tiñan unha vida breve.

A importancia cultural que Cuba adquiriu para Galicia a finais do XIX e comezos do XX é doada de entender se pensamos na cantidade de figuras relevantes que emigraron estes anos. Nomes como Manuel Curros Enríquez, Ramón de la Sagra, José Castro Chané, Alfredo Nan de Allariz, Manuel Lugrís Freire, Ramón Armada Teijeiro ou Waldo Álvarez Ínsua son só algúns nomes entre moitos. O propio Curros expresaba moi ben esta sorte de «diáspora» da cultura galega cun poema na revista Galicia en 1887 :

Quen dixo que Galicia non ten arte pouco coñece noso chau paterno.

¡Ten arte, ten! O que non ten é artistas

porque os escupe para chaus alleos ${ }^{5}$.

Poucas mostras desta realidade son máis emblemáticas que o feito de que o himno galego, un poema de Eduardo Pondal ao que lle acababa de poñer letra o compositor Pascual Veiga, se escoitase por primeira vez na Habana, concretamente na sede do Centro Galego (hoxe Gran Teatro da Habana), o 20 de decembro de 1907. O principal impulsor da iniciativa foi Xosé Fontenla Leal, outro destacado intelectual galeguista afincado na illa. Pero isto non foi máis que o símbolo de algo moito maior: libros publicados, representacións teatrais, concertos

5 Recollido en Carlos Casares (ed.) (1980): Curros Enríquez: conciencia de Galicia, Vigo, Galaxia, 150. 
e diversas representacións da cultura popular galega acadaron unha gran riqueza na capital da illa caribeña, axudando a reforzar unha identidade comunitaria que se retroalimentou coa que existía na terra de orixe. Dende ela, unha figura tan senlleira do galeguismo como Manuel Murguía louvou en diversas ocasións o labor feito dende Cuba, que consideraba un exemplo «de nuestro poder como nación, y de nuestro provincialismo como hijos de Galicia» ${ }^{6}$.

\section{A INFLUENCIA CUBANA NOS COMEZOS DAS IRMANDADES}

A identificación dos emigrantes galegos en Cuba como unha comunidade diferenciada, que se vía reflectida no que deixara atrás, foi o que permitiu esa consolidación de estruturas sociais e culturais que acabarían sendo decisivas no xurdimento do nacionalismo galego. O especial entusiasmo da comunidade emigrante e os notables medios organizativos de que dispuña, que acotío superaron os existentes na propia terra, favoreceron este proceso. Dentro del, o idioma foi un elemento decisivo, como explicou de forma moi acertada Xosé Luís Axeitos:

A primeira bandeira que levanta a Galicia emigrante non é a da franxa azul, é a do idioma. Miles de galegos alonxados da súa terra, na Habana nomeadamente, decátanse, cando se reúnen nos parques públicos e nos almacéns, que son identificados pola lingua que empregan: sen símbolos externos para identificarse, a lingua é a clave da identidade ${ }^{7}$.

A preservación e revalorización social da lingua foi un dos grandes cabalos de batalla do galeguismo destes anos, e dous dos seus principais fitos dos primeiros

\footnotetext{
6 Manuel Murguía (1891): «El Centro Gallego de La Habana», La Patria Gallega, 15 de abril, 2.

7 Xosé Luís Axeitos (2016): «As Irmandades da Fala no seu centenario: as orixes e a conexión cubana», en Carme Fernández Pérez-Sanjulián (ed.), As Irmandades da Fala, cen anos despois, A Coruña, Universidade, 25-35.
} 
anos do século XX, a fundación da Real Academia Galega e a creación das Irmandades da Fala, estiveron directamente vencellados co idioma. En ambos os casos a emigración cubana tivo un papel decisivo e, de feito, a primeira institución foi promovida pola Asociación Iniciadora y Protectora de la Academia Gallega, fundada en 1905 no edificio de Prado y Dragones, na Habana, sobre todo polos esforzos de Xosé Fontenla Leal e Manuel Curros Enríquez. Os obxectivos principais da iniciativa foron promover o idioma galego e o seu emprego máis alá da fala, elaborar un dicionario e unha gramática da lingua, estudar as ciencias, cultivar as artes escritas en galego, recoller cantos populares, tradicións e monumentos e realizar outros labores relacionados coa cultura galega. Nun artigo na revista Galicia, Fontenla defendía así o interese do proxecto:

Desde hace muchísimos años viene siendo tema de constante preocupación para algunos hombres de letras de nuestra patria, el establecimiento de una «Academia gallega», necesidad sentidísima, hoy más que nunca, por la acción destructora que extrañas influencias van ejerciendo sobre nuestro dulce lenguaje y sobre las costumbres y carácter de nuestro pueblo.

Los beneficios que dicha Academia puede reportar á Galicia son incalculables, y comprendiéndolo así los gallegos residentes en Cuba, cuyos sentimientos altruistas y patrióticos se han manifestado en tantísimas ocasiones, dan una vez más prueba evidente de su acendrado amor á la tierra en que nacieron, con la idea surgida en un grupo de entusiastas conterráneos de la creación en Galicia de la «Academia Gallega» ${ }^{8}$.

Fica claro aquí ese sentimento de responsabilidade dos emigrantes galegos coa súa terra e cultura de orixe, así como a preocupación por evitar que se perda unha lingua que é un elemento indispensable da identidade patria. Ángel Barros, que foi presidente do Centro Galego, afirmaba deste xeito a necesidade de defender

8 «Academia Gallega», Galicia. Revista Semanal Ilustrada, 9-IV-1905, 5. 
a lingua e a utilidade da Asociación Iniciadora y Protectora (AIP) no segundo aniversario da súa creación:

Conservar el idioma de nuestros mayores, sobre ser un hecho patriótico, es un signo evidente de fortaleza. Como que en las luchas eternas de las razas, lo mismo en los días de paz que en los de guerra, el idioma es lo primero que perece [...]. Cuba y Galicia tienen entre sí muchos puntos de vista enteramente afines: el patriotismo inmaculado de sus hijos y la belleza paradisíaca de su suelo?.

A achega cubana á Academia Galega non estivo só na xénese, senón que o apoio financeiro continuou despois de que botase a andar e foi decisivo para o eficaz funcionamento da institución. Por exemplo, a Asociación Iniciadora aportaba 350 pesetas anuais, que permitiron alugar na Coruña un piso que foi a sede social da Academia ata 1919, ano no que o Concello da cidade lle concedeu un lugar no pazo municipal de María Pita ${ }^{10}$. Tamén se subvencionou dende A Habana a publicación do dicionario da Academia. Nunha carta de xullo de 1912, na AIP mostráronse moi orgullosos de recibir o primeiro fascículo dunha «obra que [levantó] el entusiasmo regional».

A maior preocupación en Cuba pola defensa da lingua tamén se aprecia na reclamación da Asociación Iniciadora y Protectora, en 1916, de que as comunicacións entre eles sexan sempre en galego e, en xeral, que o sexan todas, agás as destinadas a entidades oficiais ou que non estivesen integradas por galegos ${ }^{11}$. A carta na que pide isto é de especial interese porque, ademais de destacarse a sexta parte do dicionario da lingua galega que se seguía creando, nela se proxecta

\footnotetext{
9 Ángel Barros (1907): «Discurso pronunciado en la velada literario-musical celebrada en la Habana el 4 de Septiembre de 1907 con motivo del segundo aniversario de la constitución de la Academia», Boletín de la Real Academia Gallega, II:18, 123-124.

${ }^{10}$ Axeitos, «As Irmandades...», p. 28.

${ }^{11}$ Ibídem, pp. 33-34.
} 
o apoio á Irmandade da Fala da Coruña mesmo antes de que esta se constituíse, co que se volvía demostrar a forza que se facía dende Cuba a prol de iniciativas que estaban a cambiar o galeguismo e a dar un paso máis no seu desenvolvemento: «Acordouse ofrecerlle o noso apoyo e concurso e prestarnos a representalo n'esta illa â Liga d'Amigos do Idioma, a cuyo cumprimento mandamoslle oxe a nosa adhesion e pidindolle o reglamento e instruccións» ${ }^{12}$.

Outra boa mostra da magnitude do apoio cubano á Academia é que na altura de 1917 aquel supuña o 96 \% dos fondos da institución, para baixar no 1918 ao 65 \% e, no 1919, ao $32 \%$ \% . Isto non se debeu só ao incremento das fontes de financiamento na propia Galicia, senón tamén á cada vez maior influencia de Bos Aires, que estaba a converterse no principal centro da diáspora galega. Alén da achega económica, a Asociación Iniciadora y Protectora chegou a ter en Cuba 433 socios -o que era unha cifra moi salientable-, dos que 374 residían na Habana; unha nova demostración do papel da capital. Ademais, moitas das principais figuras da elite intelectual galeguista que viviron en Cuba forxaron as súas armas no seo desta asociación. Entre os nomes máis destacados estaban o vate Ramón Cabanillas, a xornalista de orixe galega Mercedes Vieito Bouza, o xornalista Roberto Blanco Torres, o historiador Ramón Marcote ou o xornalista Antón Villar Ponte ${ }^{14}$. O capítulo de Emilio Xosé Ínsua neste volume exímeme de estenderme de vagar neste punto.

A respecto das Irmandades foi especialmente importante a pegada cubana en Antón Villar Ponte, o seu fundador e un dos grandes líderes do nacionalismo galego. O escritor e xornalista establecérase en Cuba en 1908 e alí dirixiu un semanario en Camagüey e outro na Habana, ademais de colaborar no Diario Español e na revista Alma Gallega. Regresou ao pouco tempo a Galicia, onde xa estaba de volta no 1910, para se converter nun dos principais impulsores da Real

\footnotetext{
12 Cit. en Axeitos, "As Irmandades...», p. 34.

13 Núñez Seixas, Emigrantes, caciques e indianos..., p. 88.

${ }^{14}$ Ibídem, p. 90.
} 
Academia Galega, en cuxa xénese el mesmo traballara dende a emigración. Alén diso, en 1916 promovería a campaña para poñer en marcha as Irmandades da Fala e publicaría o seu influente Nacionalismo gallego. Nuestra afirmación regional, ao tempo que seguía en contacto con moitos galeguistas da outra banda do Atlántico. A experiencia cubana permitiulle a Villar Ponte coñecer ben diversas tendencias galeguistas e incrementar a súa formación, e mesmo entrar en contacto coa práctica masónica, que tamén influiría nel ${ }^{15}$.

A tendencia predominante dentro do galeguismo en Cuba nestes anos seguía a ser o rexionalismo, que era maioritario tanto no Centro Galego como na AIP, pero tamén resulta salientable o papel do agrarismo. Dende comezos de século este movemento deixou sentir o seu eco entre os galegos da illa, labregos de orixe na súa inmensa maioría e, por tanto, preocupados pola cuestión foral e polo progreso da agricultura nas súas respectivas bisbarras natais, ás que moitos volveron como retornados. Destacou nese senso, por exemplo, a actividade de Solidaridad Gallega e de Acción Gallega, e persoeiros como Basilio Álvarez ou Ramón Cabanillas impartiron palestras na Habana que estenderon unha certa conciencia rexionalista, á par da mensaxe agraria. Entre os principais temas tratados por Basilio Álvarez na súa influente xeira cubana en 1913 estiveron a cuestión da propiedade da terra, o clientelismo e a necesidade dunha rexeneración rexional. Precisamente ese ano publicouse na Habana Abriendo el surco, unha obra cun afervoado ton revolucionario na que o cura de Beiro instaba ao campesiñado a mobilizarse contra o centralismo e mais o réxime foral. Dalgunha maneira, Álvarez consideraba que os galegos cubanos tiñan de ser os que dirixisen a loita. Con este ton definía o crego ourensán a situación dese campesiñado que a miúdo acababa por emigrar:

${ }^{15}$ Carlos C. Biscainho-Fernandes, «As Irmandades da Fala e a masonaría», en Fernández Pérez-Sanjulián (ed.), As Irmandades da Fala..., p. 75. 
Perdidas por completo las cosechas, roto el intercambio entre gobernantes y gobernados, acuciados por la acción pertinaz del fisco, agarrotados por la usura, sin comunicación para transportar los escasos productos de la tierra, faltos de un proteccionismo necesario, aplastados por el pie del cacique, sostenidos apenas por el agua que el unto enturbia, perseguidos, vejados con saña loca, no ven otro girón añil que el trozo de mar donde se balancea el barco que ha de traerlos a América ${ }^{16}$.

\section{A CREACIÓN DAS IRMANDADES E A REPERCUSIÓN EN CUBA}

A xa referida figura de Antón Villar Ponte é central para entender as orixes do nacionalismo galego e tamén un dos mellores exemplos desta conexión que existía aos dous lados do Atlántico. El e mais o seu irmán Ramón convocaron en maio de 1916 a asemblea na que se acordou definitivamente a creación dunha «Irmandade de Amigos da Fala». Tivo lugar no local da Real Academia Galega e asistiron galeguistas tan destacados como Manuel Lugrís Freire, Luís Porteiro Garea, Francisco Tettamancy, Uxío Carré Aldao ou Florencio Vaamonde Lores. O propio Antón Villar Ponte foi elixido primeiro conselleiro. Pouco despois, aínda no mesmo maio, creábase a de Santiago e logo iríanse sumando as doutras localidades galegas como Monforte, Pontevedra, Ourense ou Vilalba. O avance territorial foi imparable e en poucos anos acadáranse as 28 Irmandades, pero a maior parte delas con moi poucos afiliados, e a única dun tamaño considerable foi a da Coruña. Entre 1916 e 1922 o conxunto das Irmandades só alcanzou os 700 afiliados, unha cifra relativamente cativa se a comparamos co impacto que tiveron no eido cultural.

O idioma estivo no centro de todo este proceso, igual que estivera no proceso de cohesión comunitaria na emigración que tan relevante terminou por resultar.

${ }^{16}$ Basilio Álvarez (1976): Abriendo el surco: manual de lucha campesina, Madrid, Akal, 132 [A Habana, 1913]. 
As Irmandades érano «da fala», nos seus obxectivos sempre aparecía a defensa da lingua propia como prioridade e o texto que foi adoptado como o seu himno nesta primeira etapa, a Cántiga dos amigos da fala de Manuel Lugrís Freire, deixaba ben ás claras o valor que se lle daba:

$\mathrm{Na}$ fala gallega vive

A ialma da nosa terra;

A redención de Galicia

Nos seus acentos latexa.

Pobo que o seu verbo esquece

É traidor á natureza;

Como irmáns todos falemos

A nobre fala gallega.

Amigos da fala somos,

I-o amor de Galicia sea,

Xa que de todos é nai,

Quen nos xunte e nos protexa ${ }^{17}$.

En novembro de 1916 saíu do prelo A Nosa Terra, voceiro das Irmandades, dirixido por Antón Villar Ponte e elaborado integramente en galego. Arrincou con 2000 subscritores, moitos deles da emigración, radicados sobre todo na Habana e en Bos Aires. De feito, a publicación apareceu como Idearium da Hirmandade da Fala en Galicia e nas colonias gallegas d'América e Portugal, o que demostra ata que punto a Galicia exterior era tida en conta.

Nos primeiros meses a comunidade galega en Cuba acolleu en xeral a creación das Irmandades con entusiasmo, e tiveron adhesións tan relevantes como as do Centro Galego ou a Asociación Iniciadora y Protectora. Por exemplo, en abril

\footnotetext{
${ }^{17}$ Manuel Lugrís Freire (1919): Versos de loita, A Coruña, Tipografía de El Noroeste.
} 
José María Gil, secretario desta última, envioulle unha carta a J. B. Cerdeira, director da revista Galicia, na que lle indicaba: «Meu siñor: Na xunta que celebrou a Direutiva d'a nosa Asociación acordou entre outras cousas adherirse a os nosos hirmans que fundaron alo en Galicia a Liga d'Amigos do Idioma e pedirlle a sua representación n'esta Isla» ${ }^{18}$.

Galicia, de feito, foi a publicación que de xeito máis decidido se aliñou coas Irmandades, e deixaría atrás o rexionalismo no que se movían a maior parte das publicacións para entrar na órbita nacionalista. En palabras de Fuco Gómez -personaxe do que se tratará máis adiante-, converteuse no «periódico dos galegos reformistas ${ }^{19}$. Con todo, a maior parte da prensa galega na emigración recollía animada os diferentes avances. En xuño de 1917 Eco de Galicia publicou un texto asinado co alcume Pardo de Cela no que salientaba o labor realizado pola institución dende a súa fundación, incluíndo a constitución de delegacións en Bos Aires, Montevideo e Río de Xaneiro. Porén, apuntaba xa algo que se reiteraría nos anos seguintes: a ausencia dunha Irmandade na capital cubana, algo para moitos incomprensible pola relevancia que esta tiña na cultura galega:

Aquí en la Habana nada se ha hecho y para ello tienen la palabra los señores C. Añel y José Fontela [sic]; el primero presentó una moción en la Asamblea de Apoderados, pidiendo, si mal no recordamos, se celebre, anual o mensualmente, una sesión, hablando en nuestro idioma regional, cuya moción aún no se ha discutido. Y el señor Fontela que condujo los restos del maestro Chané a la Coruña, se le comisionó para organizar en esta ciudad un comité da Hirmandade da Fala y después de un mes que ha regresado de la Coruña, creemos, que aun no ha hecho nada ${ }^{20}$.

\footnotetext{
${ }^{18}$ Cit. en Xosé María Dobarro Paz (1999): «Xulio Sigüenza, nacionalista e poeta en Cuba. Trece poemas galegos», en Rosario Álvarez Blanco / Dolores Vilavedra Fernández (eds.), Cinguidos por unha arela común: homenaxe ó profesor Xesús Alonso Montero, Santiago de Compostela, Universidade, 432.

${ }^{19}$ Ibídem, p. 432.

20 «Os amigos da Fala», Eco de Galicia, 3, xuño de 1917, 7.
} 
O escritor rexionalista Constantino Horta insistiu na mesma idea, salientando o patriotismo amosado na creación de delegacións das Irmandades polos galegos en Bos Aires, Montevideo, Chile, Brasil, Nova York, México, Madrid e Lisboa, «mientras que los gallegos de Cuba se [hallaban] dormidos y casi faltos de amor a la Región, pues no solo no [habían] establecido la patriótica Delegación, ni tampoco [habían] prestado su concurso económico a la galiciana Hirmandade da Fala, en su lucha contra el caciquismo y el centralismo absorventes ${ }^{21}$. Segundo sinalaba José Vázquez Grela un mes despois, o propio Constantino Horta realizara un chamamento en defensa da fala que o convertía no máis «autorizado» para convocar unha reunión da que saíra a delegación na Habana das Irmandades ${ }^{22}$.

Resulta sorprendente, abofé, que dende Cuba se seguise a fornecer a maior parte do orzamento da Academia Galega e, porén, non se fixese ningunha achega económica para as Irmandades cando, segundo a prensa, si as facían outras comunidades relevantes na emigración. Un dos motivos puido ser o certo receo que pouco a pouco aparecera entre os partidarios do rexionalismo moderado, ao consideraren que as Irmandades ían demasiado lonxe nos seus obxectivos. Por exemplo, no Centro Galego e na Asociación Iniciadora y Protectora houbo debates internos sobre o grao de implicación na nova organización. No entanto, cabeceiras que seguían na liña do rexionalismo, como o semanario Eco de Galicia, dedicaron bastante espazo nas súas páxinas ao labor das Irmandades. O maior punto de ruptura estivo na I Asemblea Nacionalista, realizada en Lugo (17 e 18 de novembro de 1918), que está considerada como a definitiva aparición do nacionalismo galego, marcando unha clara ruptura co rexionalismo ${ }^{23}$. As Irmandades foron a primeira institución que como tal afirmou o carácter

\footnotetext{
${ }^{21}$ Constantino Horta (1917): «Por la patria gallega», Eco de Galicia, 20 de xuño, 10.

22 José Vázquez Grela (1917): «Por nuestro idioma», Eco de Galicia, 10 de agosto, 8.

${ }^{23}$ No seu comezo, a maioría dos que entraron nas Irmandades definíanse como rexionalistas. Moitos deles reorientáronse de forma progresiva cara ao nacionalismo, o que xa se percibe claramente en 1918.
} 
nacional de Galicia e, por tanto, defenderon ideas descentralizadoras, nas que o modelo político entendido como máis viable para os seus obxectivos foi o Estado federal, no que agardaban integrar unha construción social da nación galega en clave democrática e socialmente progresista. Definiron obxectivos que só acadaron en parte, como a configuración de partidos políticos propios ${ }^{24}$, a galeguización da función pública ou a promoción das manifestacións da cultura galega autóctona. Os obxectivos máis exitosos foron os vencellados ao idioma e, neste sentido, instauraron un monolingüismo na cultura política do galeguismo que non se acadara nin co rexionalismo nin co provincialismo. Así e todo, a normalización social do galego resultou unha meta demasiado ambiciosa, igual que o eran o seu emprego no ensino ou a súa declaración como lingua cooficial. Por iso, os principais avances lográronse no eido cultural, no que o galego se consolidou moito máis alá da poesía, que no XIX fora o xénero por excelencia do Rexurdimento, e cultiváronse o ensaio, a novela, o teatro e mesmo a prosa científica ${ }^{25}$.

En xeral, a insistencia no uso do galego non xerou problemas no seo do galeguismo político, pois considerábase fundamental fomentar a lingua. Porén, tamén apareceron algunhas voces discordantes, moitas delas publicadas en Cuba. Boa parte da prensa galega fíxose eco dunha entrevista que o dramaturgo en castelán Manuel Linares Rivas concedeu ao xornal Eco de Galicia, na que afirmaba que o teatro galego non tiña vida polo idioma e se queixaba por non estar ben considerado ao facer teatro galego en castelán: «Yo no soy bien visto por los miembros de la Academia Gallega ni por los de las "Irmandades d'a Fala”. Me miran de soslayo porque no escribo mis obras en gallego. ¡Como si

\footnotetext{
${ }^{24}$ Os intentos por presentárense ás eleccións e obteren representación foron case infrutuosos ata 1931, o que demostra que a influencia sociopolítica do galeguismo era moi inferior á cultural. A creación do Partido Galeguista en decembro de 1931 é precisamente a que marca a fin da época das Irmandades, pero esta formación política derivou delas de maneira directa.

${ }^{25}$ Neste proceso tería moita importancia o Seminario de Estudos Galegos, creado en 1923, que centralizou os intentos por prestixiar o galego no eido da investigación.
} 
para hacer obras galleguistas fuera preciso escribir en gallego!». Esta polémica resulta moi interesante para comprobar que existían contrapuntos á corrente maioritaria na identificación entre as ideas galeguistas e o idioma ${ }^{26}$. Curiosamente, foi o galeguismo da Habana o que con máis insistencia defendeu este emprego único do galego e o que fixo que a Academia Galega o adoptase como norma ${ }^{27}$. Neste sentido, hai que entender a preocupación do galeguismo cubano por que o idioma propio non recuase nun territorio dominado polo castelán. No mesmo Eco de Galicia atópanse diversos exemplos, como o artigo do xornalista e mestre José Vázquez Grela en agosto de $1917^{28}$, no que facía un chamamento aos galegos da illa para que non deixasen de empregar o seu «idioma regional»:

El idioma es la raíz de la personalidad social y jurídica de los pueblos, y los gallegos que aspiramos a descentralizar nuestra región hasta gobernarnos autonómicamente, tenemos que hacer porque nuestro verbo de libertad penetre en todos los pechos gallegos, haciéndoles ver que tenemos un dulce idioma, unos paisajes naturales y unos caudalosos ríos que solo son nuestros, y una literatura propia que brilla como la luz en las corrientes artísticas del Universo ${ }^{29}$.

Eco de Galicia e outros xornais da illa informaron acotío de novas e actividades relacionadas coas Irmandades, sobre todo se estaban vencelladas á comunidade galega inmigrada en $\mathrm{Cuba}^{30}$.

\footnotetext{
${ }^{26}$ Laura Tato Fontaíña, «Polémicas e desencontros arredor do teatro», en Fernández Pérez-Sanjulián (ed.), As Irmandades da Fala..., p. 221.

${ }^{27}$ Xosé Neira Vilas (2000): «Presencia da lingua galega na illa de Cuba», en Concepción Fontenla San Juan / Manuel Silva (eds.), Galicia-Cuba: un patrimonio cultural de referencias y confluencias: actas do Congreso celebrado en Santiago de Compostela, 24-26 de marzo, 1999, Sada, Ediciós do Castro, 122.

${ }^{28}$ De feito, Vázquez Grela foi outro dos que apuntaron en varias ocasións a idea de facer unha delegación das Irmandades na Habana.

${ }^{29}$ José Vázquez Grela (1917): «Por nuestro idioma», Eco de Galicia, 10 de agosto, 8.

30 Por exemplo, o xantar co que foi agasallado o representante do Centro Galego da Habana en xullo de 1918: vid. Eco de Galicia, 10-VII-1918, p. 4.
} 


\section{AS IRMANDADES CHEGAN Á HABANA}

As Irmandades da Fala estendéronse con rapidez polas principais cidades e vilas galegas. A Habana, en moitos aspectos, era outra cidade galega, polo que, como xa adiantamos, dende moi axiña se pensou na posibilidade de que alí houbese unha Irmandade. Un bo exemplo é un texto do Eco de Galicia de agosto de 1917, no que se aludía á constitución da delegación das Irmandades en Cuba ${ }^{31}$. O primeiro intento tivo lugar xa nese ano da man de Xulio Sigüenza, un rapaz coruñés emigrado; porén, a súa transcendencia foi tan cativa que nin apareceu recollida na prensa da época. Só sabemos que tivo algúns afiliados soltos ${ }^{32}$.

En xullo de 1918 editouse un manifesto co título As Irmandades da Fala aos galegos residentes $n$-as Américas, no que se tentaba trazar unhas liñas específicas que seguir para as comunidades da diáspora. Entre outras cousas, establecíanse catro seccións nas que debían organizarse: Cultura e Fala, Economía e Estudos Sociais, Agraria e Política ${ }^{33}$. Así e todo, a adhesión cubana ás Irmandades foi de vagar. Había sectores moi favorables, en especial grupos nacionalistas que foron aparecendo, pero en parte do rexionalismo víronse con certo receo. O influente semanario Eco de Galicia recolleu dende moi axiña as súas actividades, pero tardou en amosarse directamente favorable. O Centro Galego, pola súa banda, sumouse a comezos de 1919, despois de chegaren as novas da Asemblea de Lugo. Aínda que internamente había dúbidas polo medo ao independentismo, deuse un paso cara adiante ${ }^{34}$. Algo semellante sucedeu coa Asociación Iniciadora y Protectora, que nun primeiro momento se mantivo bastante á marxe pero en 1919 se sumou de maneira pública á obra das Irmandades en Galicia ${ }^{35}$.

\footnotetext{
31 Vázquez Grela, «Por nuestro idioma».

32 Núñez Seixas, Emigrantes, caciques e indianos..., p. 109.

33 Dobarro Paz, "Xulio Sigüienza...», p. 434.

${ }^{34}$ Núñez Seixas, Emigrantes, caciques e indianos..., p. 110.

35 «Vida de la colonia», Eco de Galicia, 9-III-1919, p. 10.
} 
Malia recibir diversas adhesións, o que continuaba sen xurdir na Habana era unha organización que seguise o exemplo das Irmandades, mentres que, por exemplo, en Bos Aires estaba a destacar o papel da Asociación Regionalista A Terra, fundada en 1918. Tiña unha liña claramente rexionalista, pero coincidía en moitos dos seus obxectivos cos das Irmandades, incluíndo o do idioma, que se definía con nitidez no seu programa:

\begin{abstract}
Siendo el idioma un elemento eficaz para sostener en la debida tensión el amor hacia la región, esta entidad procurará cooperar a la altruista labor que desempeñan las IRMANDADES DA FALA, aconsejando y propagando entre sus afiliados el uso del idioma gallego, pero sin que ello indique otras aspiraciones que el deseo natural de conservar una lengua que consideramos como base esencial de nuestra personalidad y de nuestras costumbres ${ }^{36}$.
\end{abstract}

Incidir na diferenza coa situación que se daba na Arxentina foi moi común na prensa galeguista cubana, que ollaba para o sur con certa envexa. Porén, en 1920 víronse os pasos definitivos cara a unha verdadeira delegación cubana das Irmandades. Estas últimas xa tiñan un delegado en Cuba, Manuel Monteiro, mais a presenza de varios membros recentemente inmigrados, como Tomás Rodríguez Sabio, procedente da Irmandade da Coruña, e o intenso labor do xornalista José Cerdeira, director da revista Galicia, axudaron a dar o empurrón definitivo ${ }^{37}$. Así, en abril de 1920 este voceiro sinalaba: «En breve se constituirá en esta capital una nueva entidad regional que se inspira en los ideales de las "Irmandades da Fala" y del "Partido Nazonalista" de nuestra región", ben como que «han prometido su concurso gran número de gallegos jóvenes y entusiastas que harán de esta agrupación el portaestandarte de los ideales galicianos»,

\footnotetext{
${ }^{36}$ A los gallegos, febreiro de 1918, Establecimiento Gráfico La Iberia, p. 2.

${ }^{37}$ Núñez Seixas, Emigrantes, caciques e indianos..., p. 111.
} 
ademais de indicar que as adhesións podían dirixirse á redacción da propia revista $^{38}$.

O 20 de xuño de 1920 tivo lugar a primeira xunta xeral da Xuntanza Nazonalista Galega (XNG) nos locais da Agrupación Artística Gallega da Habana. Nela participaron salientados personaxes de traxectoria galeguista na colectividade, como Fuco Gómez, Tomás R. Sabio, J. Liste Mourenza, José Benito Cerdeira ou Andrés Rodríguez Orjales. Este último foi escollido conselleiro primeiro da nova agrupación, e Fuco Gómez, viceconselleiro. Aínda que non se empregou a denominación de "Irmandade», é evidente que funcionou como unha máis delas. De feito, a organización rexíase "pol-o regramento das Irmandades da Fala aprobado pol-o Señore Gobernador d'a provincia d'Habana». Ademais, fixo seus os manifestos aprobados nas asembleas de Lugo e Santiago polo Partido Nazonalista Galego ${ }^{39}$. Isto abonda para podérmola considerar como a primeira irmandade propiamente dita que se creou alén mar. Entre os seus principais obxectivos figuraba a galeguización das sociedades de emigrantes, para que estas ofrecesen nos plans educativos por elas sostidos unha educación máis galeguista e fomentasen o emprego do idioma, así como enfrontarse ás visións pexorativas sobre os galegos que a miúdo imperaban na esfera pública cubana ${ }^{40}$. Outro eixe central da organización foi favorecer a difusión da cultura galega entre os inmigrantes a través de festas, representacións teatrais ou eventos musicais. Para iso colaboraron adoito con asociacións como a Agrupación Artística Gallega ou a Juventud Gallega da Habana ${ }^{41}$.

A partir de 1921 a XNG adquiriu maior forza e ampliou de forma notable o seu impacto, para superar ao cabo os cen militantes. Tamén conseguiu ter unha sucursal en Santiago de Cuba, boa mostra desa maior relevancia ${ }^{42}$, e lanzou un

\footnotetext{
${ }^{38}$ Cit. en Dobarro Paz, «Xulio Sigüenza...», p. 434.

39 Tamén polos que esta colectividade aprobará no sucesivo (o de Lugo aparece en Eco de Galicia, 16-II-1919).

40 «A Xuntanza Nazonalista Galega d'Habana aos galegos do desterro», Galicia, 25-VII-1920, 16-17.

${ }^{41}$ Núnez Seixas, O galeguismo..., p. 112.

42 Emilio Xosé Ínsua / Xurxo Martínez González (2018): Común temos a patria: biografia dos irmáns Villar Ponte, Vigo, Xerais, 299; Dobarro Paz, «Xulio Sigüenza...», p. 434.
} 
xornal propio, Nós. Órgao da Xuntanza Nazonalista Galega d'Habana, que estaba dirixido polo músico Sinesio Fraga. Todas as súas publicacións eran monolingües en galego e declarouse abertamente arredista; neste sentido, chegou a empregar un forte ton antiespañol, con frases como «ceibar Galiza do yugo opresor d'os cacicatos d'a Hespaña». Non obstante, axiña apareceron dúbidas sobre este ton. Despois de editar oito números, a revista transformouse en Terra Gallega. Órgao da Xuntanza Nazonalista Galega d'Habana e paladín do honor da Raza Céltiga, máis moderada que a súa devanceira e con bastantes anuncios, posiblemente favorecidos por ese ton máis moderado. Sinesio Fraga seguiu a dirixir a publicación, mentres que Fuco Gómez foi o seu administrador, ata que o substituíu o fotógrafo Manuel Blanco Pascual por motivos de saúde.

O primeiro número de Terra Gallega comezaba co seguinte «saúdo do director», que marcaba con claridade a continuidade coa anterior publicación e se amosaba ademais respectuoso coa competencia:

Dámosllo agarimoso a todos aquel-es que, con fís nobles i outos ideás están ja no estadium periodísteco.

Lóxicamente, non podemos decire que de novo nos alcontramos na palestra, ja que nin por un anaco de tempo deixamos d'estaren'ela.

Tampouco podemos decire que iste é un idearium mais no campo d'o periodismo, pois que «TERRA GALLEGA» é a continuación d'a aquel outro idearium de grata lembranza que se chamou «NOS» que tivo a groria de sementar as pirmeiras arelas de libertade e redenzión p'ra Galizia.

Saudamos pois de novo a Prensa capitalina, irmán ou allea, desexándelles os mismos eixitos que p'ra nós queremos. Hai campo p'ara todos. Cando se labora inspirados n'un nobre ideal, non hai terra estéril nin chán improducto. Soio aquel-es, que laboran n’a sombra, e gastan as súas forzas n'a maldade son os que alcontran espiñas, e se están cavando a súa propia foxa ${ }^{43}$.

\footnotetext{
43 «Saúdo», Tierra Gallega, 1, novembro de 1921, p. 7.
} 
Neste mesmo número incluíase un texto do secretario xeral da Xuntanza Nazonalista Galega, Tomás Rodríguez Sabio, no que este sinalaba que o voceiro o era da formación e que continuaba co labor de Nós, que deixara de publicar en contra da súa vontade. Así mesmo, sinalaba que pretendían facer de Terra Gallega o órgano oficial da cultura galega en Cuba, así como idearium dos galegos que alí moraban ${ }^{44}$. Tamén escribía Sinesio Fraga, destacando o éxito da formación e o carácter máis moderno e aberto da nova publicación:

A Xuntanza Nazonalista, medra e mellora. Os espantaxos van desaparecendo e o Nazonalismo trunfando, como todal-as causas xustas.

Aquel pequeniño «Nos»-orgao que foi da Xuntanza o nacer ísta-, convirtiuse presto nunha moderna revista que será a mais culta exposizón do verdadeiro galeguismo, na Illa de Cuba; éla será a mais outra trabua desd'a que podrán expoñer a suas opiniós todol-os ceibes de prexuicios e nobres de corazón ${ }^{45}$.

Mesmo reproducían un texto de Alfonso R. Castelao no que este afirmaba que un literato que negaba a capacidade literaria do galego estaba a negar a súa propia capacidade literaria, e enxalzaba as bondades do galego como lingua literaria ${ }^{46}$. En definitiva, Terra Gallega converteuse no voceiro das Irmandades en Cuba, como demostraron as súas últimas páxinas, dedicadas decote a recoller actos e novas de Galicia e nas que as diversas actividades das Irmandades, como palestras ou representacións artísticas, recibiron unha atención preferente.

Ademais deste voceiro propio, a XNG demostrou estar ben relacionada con moitos medios xornalísticos relevantes da illa. Iso levou á aparición de numerosos artigos, entrevistas e comentarios sobre a súa ideoloxía e actividades, o que permitiu aos galegos (e tamén aos non galegos) coñecer as ideas que defendían e

\footnotetext{
44 Tomás Rodríguez Sabio: «Camiño adiante», Tierra Gallega, 1, novembro de 1921, p. 8.

45 Sinesio Fraga (1921): «Moitas Cousas», Tierra Gallega, 1, novembro de 1921, 9.

${ }^{46}$ Alfonso Daniel R. Castelao (1921): «Escoita, ti, literato rico e vanidoso», Tierra Gallega, 1, novembro, 8.
} 
o labor que realizaban. Por suposto, na prensa da comunidade galega este impacto era aínda maior, e en xornais como El Heraldo Gallego, Galicia ou Eco de Galicia a presenza de textos vencellados ao labor dos grupos nacionalistas e a reivindicacións, como unha maior autonomía para Galicia, foron unha constante. O fracaso de Terra Gallega, que non sobreviviu a 1922, deixou precisamente estes xornais como únicos «voceiros» de relevancia das opcións nacionalistas, aínda que dentro deles compartían espazo con outras opcións que non o eran.

Nesta «Irmandade» cubana unha das principais figuras foi Xulio Sigüenza, que vivía en Cuba dende 1912 e consideraba que o maior inimigo do nacionalismo galego era o analfabetismo, pero non tanto o das letras como o das ideas, e que o esforzo principal da agrupación debía ser tentar abrirlle os ollos á xente. Sigüenza incluso prevía a posibilidade de ter que loitar coas armas pola independencia, algo que a maior parte dos nacionalistas seguían rexeitando: «Non; os pobos que se amodorran no teñen dereito a ser ceibes; pr'a ser ceibe, fai falla loitar como se loita en Irlanda, como se loitou en Cuba, como loitaron todos cantos pobos aspiraron un día a se rexir pol-as suas leises» ${ }^{47}$. O mellor resumo do seu ideario fíxoo el mesmo con "Os mandamentos do bo galego», que enviou en 1921 durante unha viaxe nos Estados Unidos e que supoñen tamén un exemplo moi claro das ideas que defendía o sector máis arredista do nacionalismo galego en Cuba:

1 - Ama a Galicia sobre todal-as cousas.

2 - Pensa que en Galicia deben mandar soyo os galegos.

3 - Fala, escribe e pensa en galego.

4 - Non sexas mais que galego.

5 - Pensa c’a terra está por ceibar.

6 - Q’e obriga tua loitar pol-a sua liberazón.

${ }^{47}$ Dobarro Paz, «Xulio Sigüenza...», p. 434. 
7 - Antepón a todal-as convenenzas as convenenzas d'a terra.

8 - Non negues nunca ser galego.

9 - Traballa, pensa y-estudia o modo de conquerire a independenza d'a terra.

10 - Pensa e'obrando d'este xeito, merecerás o ditado de «bo e xeneroso» de que falou Pondal.

Estes dez mandamentos se encerran n-un só, en amar a Galicia por enriba de todo e pensar que deste xeito farase digna a palabra «galego» ${ }^{48}$.

As ideas de Sigüenza eran demasiado radicais para a maior parte do galeguismo da época, pero estaban nunha liña en crecemento que pouco a pouco ía gañando máis relevancia e adeptos. Para o escritor, o labor das Irmandades estaba sendo decisivo para lograr unha concienciación que ía máis alá do idioma e que debía permitir a emancipación de Galicia, dende un punto de vista tanto nacional como social:

A patriótica e beneditina labor d'as Irmandades d'a Fala vai evitando canto en terras galegas repersenta vicio, atraso, inmoralidá e caciquismo. É indiscutivel que a súa enérxica, intelixente e continuada autuazón débese o que pra ninguén é un segredo: a restaurazón -¡necesaria com'ó pan de comer!- d'o esprito coleitivo, denantes inutilizado pol'o escravizamento d'o centralismo baixa e cobardemente exercido por quenes d'a política facían medio d'enriquecerse a conta d'os bens nacionales e dos intereses particolares ${ }^{49}$.

Outra figura central neste proceso foi o xa aludido inmigrante natural de Becerreá Fuco Gómez. Da súa man aparecera na Habana en 1921 o primeiro grupo que se definiu nidiamente como independentista: o Comité Revoluzonáreo Arredista Galego (CRAG). A formación apenas tivo un par de anos de vida e resulta difícil de rastrexar polo seu carácter clandestino. Do pouco que sabemos

\footnotetext{
48 «Os mandamentos do bo galego», Galicia, 1, 1-1.

${ }^{49}$ Cit. en Dobarro Paz, «Xulio Sigüenza...», p. 433.
} 
é que editaron varios panfletos, con proclamas revolucionarias nas que se chamaba á independencia de Galicia. Fuco Gómez vía necesario derrotar o réxime político da monarquía da Restauración e da ditadura primorriverista para declarar un Estado galego. Ademais, chamaba a crear comités arredistas nos países onde houbese emigración, coa idea de que estes funcionasen como células revolucionarias de carácter secreto. Para alén de gardar certa semellanza coas sociedades secretas irlandesas nos Estados Unidos, inspirábase, como os Clubs Separatistes cataláns de Cuba, no modelo do Partido Revolucionario Cubano de José Martí, tres décadas anterior. De feito, e ademais da inspiración irlandesa, moi presente no nacionalismo galego na altura, Fuco Gómez tiña tamén como referente ideolóxico o sobranceiro teórico do independentismo cubano José Martí50.

Volvendo á Xuntanza Nazonalista Galega, cómpre analizar o seu volume para calibrar a súa importancia. En 1923 tiña na illa 88 militantes, dos que 77 estaban na Habana, evidencia, unha vez máis, do peso da comunidade galega na capital con respecto ao resto de Cuba. Que non chegasen nin a un cento de militantes pode levar a crer que se trataba dunha formación marxinal dentro das Irmandades, pero de todas as que había en Galicia só a superaba en militantes a Irmandade da Coruña, polo que podemos pensar na XNG como un centro importante dentro dunha formación que tiña unha certa relevancia no eido cultural, mais unha masa social moi limitada. No relativo á mobilización conseguiron algunha visibilidade, pero en xeral os resultados foron cativos. Aproveitaron momentos concretos con certo éxito, como a represión da Garda Civil na parroquia pontevedresa de Guillarei en novembro de 1922, que se saldou con varios labregos mortos e foi empregada para demostrar o «oprobioso centralismo español» 51 . Entre os actos nos que participaron destacou o mitin de protesta organizado o 4 decembro polo Comité Representativo de las Sociedades

\footnotetext{
${ }^{50}$ Núñez Seixas, O galeguismo..., pp. 114-115. Sobre a andaina de Fuco Gómez, cf. tamén Xurxo Martínez González (2007): Fuco Gómez, Pontevedra, AGER.

${ }^{51}$ Érguete Galicia!, XNG, finais do ano 1922, cit. en Núñez Seixas, O galeguismo..., p. 116.
} 
Gallegas de Instrucción de La Habana, que tivo lugar no Centro Galego e ao que asistiron máis de 2000 persoas $^{52}$, destacando nel a intensa intervención de Fuco Gómez ${ }^{53}$.

Dentro das Irmandades galegas había diversas tendencias, que se foron agrupando en dous bloques e levaron a unha escisión en febreiro de 1922, na IV Asemblea Nacionalista, realizada en Monforte. Por un lado ía quedar a Irmandade da Coruña e, por outro, a nova Irmandade Nazonalista Galega, que era contraria á participación electoral. A maior parte das Irmandades ficaron encadradas nesta nova organización, presidida por Vicente Risco, incluíndo a Xuntanza Nazonalista da Habana ${ }^{54}$, que moi rapidamente se puxo do seu lado e sería unha colaboradora moi activa.

Dende 1923 a situación da XNG foi tornándose cada vez peor. Varias crises internas e disputas entre os seus membros foron rachando a cohesión, e a chegada da ditadura de Primo en España debilitou as Irmandades en xeral, para afectar tamén á cubana, entre outras cousas porque se frearon as relacións que esta tiña coas que operaban en Galicia. Neste contexto foise esvaecendo e, malia que en 1924 aínda desenvolvía diversas actividades culturais, en 1925 acabou por desaparecer. Houbo un intento de reaparición en 1926 como Irmandade Nazonalista da Habana, pero o proxecto disipouse moi rápido. Desde entón xa non haberá máis intentos deste tipo, aínda que algúns dos membros, como Fuco Gómez, seguiron activos.

A debilitación e a definitiva desaparición da XNG terminaron de confirmar que Bos Aires desprazara A Habana como centro principal da comunidade galega

\footnotetext{
52 Para termos una idea, segundo algúns cálculos en 1922 había en Cuba arredor de 150000 inmigrantes galegos: Abel Losada (1999): Cuba: población y economía entre la independencia y la revolución, Vigo, Universidade, 121-135. E na altura de 1919 o Centro Galego da Habana tiña uns 50000 membros, o que mostra a súa inmensa relevancia entre a comunidade galega na illa (Núñez Seixas, "Galician Immigrant Societies...", p. 710).

53 Galicia, 9-XII-1922.

54 Justo Beramendi (2007): De provincia a nación: historia do galeguismo politico, Vigo, Xerais, 679.
} 
de ultramar ${ }^{55}$. Na capital arxentina imitárase o exemplo habaneiro e creárase a segunda Irmandade na emigración, que neste caso si que empregou directamente o nome: a Irmandade Nazonalista Galega, fundada en 1923 por Eduardo Blanco Amor e Ramiro Isla Couto. Xa tivera lugar a Asemblea de Monforte, polo que seguiu dun xeito directo á organización homónima que xurdira daquela ruptura no seo das irmandades.

\section{CONCLUSIÓNS}

A colectividade galega de Cuba tivo un papel decisivo na aparición do nacionalismo galego. As asociacións alí fundadas mantiveron e recrearon unha conciencia identitaria galega que adquiría máis forza e relevancia polo feito de estaren lonxe do país. Esa conciencia identitaria tivo no idioma o seu eixe vertebrador, por entenderse que era un dos trazos étnicos que máis contribuían a definir a personalidade galega e cuxa perda máis de lamentar sería. Por iso, cumpría protexela e valorizala. De feito, en dous fitos tan fundamentais para o galeguismo como foron a creación da Academia Galega e a das Irmandades da Fala, a lingua foi o elemento capital. E precisamente estas dúas institucións forxáronse en boa medida na Habana, que demostrou ser, nas dúas primeiras décadas do XX, o principal foco irradiador de cultura e identidade galegas do outro lado do Atlántico.

A relación entre Cuba e as Irmandades foi de ida e volta. Se ben esta organización non se xestou na illa, como o fixera a Academia Galega, o seu principal impulsor, Antón Villar Ponte, tivo un paso por ela que lle deixou unha gran pegada e do que tirou moito partido, ao entrar en contacto con tendencias que

\footnotetext{
55 A diferenza do que daquela acontecería en Arxentina, en Cuba o galeguismo de tendencia nacionalista veríase superado por un «rexionalismo folclórico» máis baseado na gabanza de figuras históricas galegas que noutros elementos: José Antonio Vidal Rodríguez (2008): A Galicia antillana: formación e destrución da identidade galega en Cuba, 1899-1968, Santiago de Compostela, Fundación Pedro Barrié de la Maza, 256.
} 
ideoloxicamente ían un paso por diante das que había en Galicia. No proceso de creación das Irmandades e de evolución do galeguismo houbo unha división (e non tanto un enfrontamento) entre o vello rexionalismo e o incipiente nacionalismo. Case todo o espectro do galeguismo bambeou entre un e outro extremo; dende finais da década de 1910 deuse unha progresiva transferencia do primeiro polo ao segundo.

Aínda que na illa de Cuba a creación das Irmandades foi moi ben acollida polos medios da colectividade galega, a lentitude en formar unha delegación desacougou non poucos galeguistas, que mesmo crían que estaba a quedar en dúbida o patriotismo da comunidade inmigrante. Non obstante, iso compensouse coa creación na Habana da primeira Irmandade fóra de Galicia. A Xuntanza Nazonalista Galega tivo unha vida breve, de 1920 a 1925, mais tamén revestiu certa relevancia, pois contribuíu a que se avanzase en obxectivos básicos deste paso adiante do galeguismo, como foron o monolingüismo, a definición nacional de Galicia cunha clara oposición fronte ao Estado-nación español ou a loita social en defensa da clase traballadora no urbano e no rural.

A perda de peso de Cuba como país receptor de inmigrantes galegos, en favor sobre todo de Bos Aires, e mais o cambio político de 1923 en España, que freou os avances do galeguismo no país e as relacións coas asociacións de alén mar, levaron a un arrefriamento dese nacionalismo que se organizara na illa caribeña. Malia os esforzos de figuras como Fuco Gómez, que mantivo unha incesante actividade ata a década de 1940, A Habana deixou de ser a capital do galeguismo como o fora anos antes. Con todo, a comunidade galega alí afincada seguiu a manter unha forte conciencia identitaria, de fondas raizames. 


\section{REFERENCIAS BIBLIOGRÁFICAS}

Álvarez, Basilio (1976): Abriendo el surco: manual de lucha campesina, Madrid, Akal [A Habana, 1913].

AXEITOS, Xosé Luís (2016): "As Irmandades da Fala no seu centenario: as orixes e a conexión cubana», en Carme Fernández Pérez-Sanjulián (ed.), As Irmandades da Fala, cen anos despois, A Coruña, Universidade, 25-35.

BERAMENDI, Justo (2007): De provincia a nación: historia do galeguismo politico, Vigo, Xerais.

Biscainho-Fernandes, Carlos Caetano (2016): «As Irmandades da Fala e a masonaría», en Carme Fernández Pérez-Sanjulián (ed.), As Irmandades da Fala, cen anos despois, A Coruña, Universidade. 73-97.

Cabo Villaverde, Miguel (1998): O agrarismo, Vigo, A Nosa Terra.

CASARES, Carlos (ed.) (1980): Curros Enríquez: conciencia de Galicia, Vigo, Galaxia.

Dobarro Paz, Xosé María (1999): «Xulio Sigüenza, nacionalista e poeta en Cuba. Trece poemas galegos», en Rosario Álvarez Blanco / Dolores Vilavedra Fernández (eds.), Cinguidos por unha arela común: homenaxe ao profesor Xesús Alonso Montero, Santiago de Compostela, Universidade, 433-444.

Dobarro Paz, Xosé María (2001): «Manuel Curros Enríquez, José Fontenla Leal e a Real Academia Galega: observacións e datos sobre as súas orixes e vicisitudes», Boletín da Real Academia Galega, 362, 203-266.

Fontenla San Juan, Concepción / Manuel Silve (eds.) (2001): Galicia-Cuba: un patrimonio cultural de referencias y confluencias, Sada, Ediciós do Castro.

ÍnSUa López, Emilio Xosé (2016): A nosa terra é nosa!: a xeira das Irmandades da Fala (1916-1931), A Coruña, Baía.

Ínsua López, Emilio Xosé / Xurxo MarTínez GonzÁlez (2018): Común temos a patria: biografía dos irmáns Villar Ponte, Vigo, Xerais.

LOSADA, Abel (1999): Cuba: población y economía entre la independencia y la revolución, Vigo, Universidade.

Lugrís Freire, Manuel (1919): Versos de loita, A Coruña, Tipografía de El Noroeste.

Martínez GonzÁlez, Xurxo (2007): Fuco Gómez, Pontevedra, AGER.

Neira VILAS, Xosé (2000): «Presencia da lingua galega na illa de Cuba», en Concepción Fontenla San Juan / Manuel Silva (eds.): Galicia-Cuba: un patrimonio cultural de referencias y confluencias, Sada, Ediciós do Castro, 119-125.

NúNEZ SEIXAS, Xosé M. (1998): Emigrantes, caciques e indianos: o influxo sociopolitico da emigración transoceánica en Galicia (1900-1930), Vigo, Xerais.

NúÑez SeIXAS, Xosé M. (1992): O galeguismo en América, 1879-1936, Sada, Ediciós do Castro.

NúNEZ SeIXAS, Xosé M. (2019): «Galician Immigrant Societies in Cuba: Local Identity, Diaspora Politics and Atlantic Mobilization (1870-1940)», Journal of Social History, 52:3, 705-730.

Sixirei Paredes, Carlos (1995): Galeguidade e cultura no exterior, Santiago de Compostela, Tórculo.

Tato Fontaíña, Laura (2016): «Polémicas e desencontros arredor do teatro», en Carme Fernández Pérez-Sanjulián (ed.), As Irmandades da Fala, cen anos despois, A Coruña, Universidade, 217-234.

VIDAL RodríGuez, José Antonio (2005): La emigración gallega a Cuba: trayectos migratorios, inserción y movilidad laboral, 1898-1968, Madrid, CSIC.

VIDAL Rodríguez, José Antonio (2008): A Galicia antillana: formación e destrución da identidade galega en Cuba, 1899-1968, Santiago de Compostela, Fundación Pedro Barrié de la Maza. 